\title{
The Relationship between Reflective Thinking Tendencies and Social Problem Solving Abilities of Pre-Service Teachers
}

\author{
Sadık Yüksel Sivaci \\ Correspondence: Sadık Yüksel Sivaci, Ahi Evran University, Turkey. \\ Received: March 15, 2017 \\ doi:10.11114/jets.v5i11.2273 \\ Accepted: September 14, 2017 Online Published: October 12, 2017 \\ URL: https://doi.org/10.11114/jets.v5i11.2273
}

\begin{abstract}
The ability of reflecting thinking and problem solving are two qualities that are thought effective in education of qualitative teachers and regulations of their educational status. In this study, our aim is to examine the pre-service teachers' levels of reflective thinking and problem solving and to determine if there is a significant relationship between reflective thinking and problem solving. From this aspect, this study has the quality of relational screening model. The sample of this study includes 438 pre-service teachers studying at Kurşehir Ahi Evran University in 2015-2016 academic year. As a data collecting tool, "Reflective Thinking Scale (RTS)" and "Problem Solving Inventory (PSI)" have been used. In the study, it was seen that pre-service teachers had a moderate and above positive relationship between the reflective thinking tendencies and the scores they got from the subscales of the problem solving skills and the general scores they got from the scales. It was determined that there is a significant positive relationship between reflective thinking and problem solving. In general, it is concluded that the pre-service teachers' abilities of reflective thinking and problem solving are high.
\end{abstract}

Keywords: reflective thinking, problem solving, teacher education, pre-service teachers

\section{Introduction}

The world has been trying to catch the era and keep up with the times for a long time. Therefore, all the societies in the world try to realize this affair by learning and teaching. When it is dealt with basically, they aim to make it real with the help of teachers.

In order to reach specific standards, teachers need to have some certain qualities. These qualities; 1. Having comprehensive knowledge of creative and critical thinking system. (Semerci (2007) considers that reflective thinking includes these two features (1364)). 2. Being an individual open to self-criticism. 3. Evaluating positive criticisms and using them. 4. Knowing that reflective teaching is a way of improving teachers. 5. Not being content with just giving the necessary knowledge to the students, also controlling in what levels they get the knowledge (Erton, 2014). At this stage, the point that will be taken up is reflective thinking and problem solving which is an indivisible part of reflective thinking.

Reflection in education is defined as the ability of thinking, making choice and taking responsibilities of these choices (Ross, 1990; cited in Gözütok, 2006). The concept of reflection was enlightened by Dewey in 1933 with the purpose of explaining the education with great extent of scope and directing the emerging things and stated as a process related to the problems of teachers and trying to find a solution to these problems (Yorulmaz, 2006). When the related literature is examined, it is possible to see there are various definitions of reflective thinking. Reflective thinking is a way of thinking including the process in which an individual takes up a subject mind and evaluates it in earnest (Dewey, 1933; cited in Tican, 2013). Besides, Schön (1987) states that creative thinking consists of astonishment elements like pleasant or unpleasant situations that convey the individual from the point of reflective thinking to the conclusion. This astonishment conflicts with the individual's fund of knowledge, and the state of realisation of this is called as knowing (Hong and Choi, 2011).

According to Larrivee and Cooper (2006), the teachers who think reflectively spend more times in the class by realizing the interaction occurring in the class and they think about the conclusions seriously. On the other hand, the teachers who do not think reflectively cannot be good at comprehending dilemmas in general and consequently cannot do what is necessary for their professions (Tican, 2013). Dewey asserts four key issues about reflection in his studies and subsequent comments. First one is whether there is relationship between reflection and action. Second one is related to 
the time; it includes that reflection does not occur transiently, commonly and systematically. Third is about if the reflection is self-created and problem-focused or not. Fourth one is related to how reflection conceives solutions during the process of critical reflection (Hatton and Smith, 1995: 33-34).

It is seen that the concept of reflection has become a subject of many studies and it has quite a lot importance in teacher education (Copeland et al., 1993; Yost et al., 2000). Researches show that problem solving ability of pre-service teachers improves when they reflect their own methods (Yost et al., 2000). Afterwards, Dewey mentions the steps of reflection. These steps do not have to be sequential, but they should be compatible with each other for the reflection process. These steps are suggestions, problem, hypotheses, reasoning, and testing. Suggestions are thoughts and possibilities occurring in one's mind when an individual is stuck in a difficult situation. As this phase improves, making a decision becomes difficult and the individual's need for thinking increases. Problem is that the mind sees the whole picture to get rid of small details of disorienting situations. Hypothesis is that an individual decides what he will do by taking these suggestions into consideration. Reasoning is that an individual tries to come to a conclusion by combining his knowledge, thoughts and previous experiences. Testing can reveal the current problem as well as it can mirror possible new problems (Kızılkaya and Aşkar, 2009). In addition to this, Dewey (1933) expresses the required qualifications of an individual as open-mindedness, full-eagerness and responsibility to perform reflection (Tican, 2013).

Additionally, Rodgers (2002) explains Dewey's reflection concept in four ways: 1. Reflection associates experiences of an individual with his opinions and provides him to make these relations profoundly. As a result of this, individuals can transfer their experiences each other. 2. The basis of the reflection is a notion based on scientific researches. 3 . Reflection should occur in society and interaction with other individuals. 4. Lastly, reflection requires attitudes that evaluate personal and ideological developments of individuals (Alp and Taşkın, 2012). Besides, Bartlett (1990) asserts that Reflective Teaching process consists of five basic stages. These are 1. Examination 2. Enlightenment 3. Knowledge comparison 4. Evaluation 5. Operationalization.

When the reflective thinking in education is taken up, it is needed to give importance and pay attention to make students obtain this way of thinking in teacher education programs, and it is required to prepare activities in this way. As a result, they will be trained as the teachers who know reflective thinking. Therefore, they will be able to keep up with fluctuation in education system and will always be successful in teaching profession. When considered from this point of view, reflective thinking is quite an important thinking skill (Tican, 2013). In line with these ideas profounded up to this time, we have seen that reflective thinking is not alone and there are a lot of factors attendantly. In this case, it can be said that reflective thinking is not an autogeneous process. In reflective thinking, consciousness enters an active period by focusing on a problem. From this aspect, reflective thinking differs from daily motions (Alp and Taşkın, 2008; cited in Gedik et al., 2014). When the literature is examined, Öztürk (2003; cited in Gedik et al., 2014) defines reflective thinking as a process elapsing during the determination of problem and looking at the problem differentially while Ünver (2003) defines it as a process elapsing during thinking about solving problems.

In this sense, we apply to various tools in order to realize reflective thinking. Some of these tools are reflective writing, think aloud, group discussions, etc. Heppner explains the meaning of reflective thinking with the ability of solving and overcoming problems (Kızılkaya and Aşkar, 2009). Problem is the obstacle which hinders opportunities that an individual obtains in order to reach terminal goals. And problem solving is defined as an effort made to overcome these obstacles (Terzi, 2003). On the other hand, we have seen that the problem solving ability is defined as evaluation of the truths by determining them after feeling current difficulties and this affects our success directly (Üstün and Bozkurt, 2003). In this case, problem solving ability is an important factor which is required for having happy, peaceful and healthy life (Sonmaz, 2002; cited in Karaca, Aral \& Karaca, 2013). Individuals who can solve their own problems believe in themselves during the decision-making period and they are more enterprising in social issues (Şahin, Şahin \& Heppner, 1993). And individuals thinking they are unsuccessful in this issue are more inclined to negativities and more shy, and they also display more affective behaviors (Dixon, Heppner and Anderson, 1991; cited in Karaca, Aral \& Karaca, 2013).

Bingham (1998) sees problem solving as processes and efforts that we made to clear the way with the purpose of reaching the determined goals (Yiğit, 2013). In other words, problem solving ability is the abilities that we use in solving complex problems in our daily life (Zadnik and Loss, 1995; cited in Yiğit, 2013). And he says that we should have decision-making and problem solving abilities to lead more comfortable and peaceful life (Korkut, 2004). That the teachers are healthy in relationships, practical in problem solving and good at being role model is possible with their reaching up sufficient level in social skills. One of these social skills is problem solving ability. To contribute to the development of society, teachers should have high ability of solving problems that they encounter at school. And this is possible with teachers evaluate themselves (Güçlü, 2003: 274). Then, what path should be followed during the process of problem solving? In this process, four phases should be followed. 1. Preparation phase, 2. Incubation phase, 3. 
Comprehension or enlightenment phase, 4. Evaluation and correction phase. According to this, what the problem is determined in the first phase. Secondly, solution is not searched by thinking better solution will be found in the following phase. In the third phase, a new idea is brought forward by a snap decision. Lastly, obtained solution is tested in case it works. If the solution does not work, all the phases are re-handled and the required alterations during the resolution process are made (Morgan, 2009; cited in Genç and Kalafat, 2010).

As a result, today's society needs individuals who are creative, who are able to think practically and know how to overcome problems instead of individuals who are quite faithful to their values. In this context, problem solving contributes to individuals on the basis of their skills like displaying democratic behaviors and attitudes, critical thinking, making decision, questioning and reflective thinking (Demirel, 2004). This method should be known and used effectively by the pre-service teachers to educate a youth who can solve the problems instead of a youth creating problem. Teachers should know that individuals have different perceptions and ages, so they should support the individual's problem solving ability rather than imposing determined solutions of the problems (Dona et al., 1997; cited in Saracaloğlu et al., 2009). Reflective thinking and problem solving ability are two qualities that are thought effective in the education of qualified teachers and in the regulations of their educational status. In the study, it is aimed to examine reflective thinking and problem solving levels of pre-service teachers and to determine whether there is a significant relationship between reflective thinking and problem solving. In order to research this question, the following sub-questions were formed:

1. In what level are the reflective thinking tendencies of pre-service teachers?

2. In what level are the social problems solving abilities of pre-service teachers?

3. Is there any relationship between the sub-factors of reflective thinking tendencies of pre-service teachers and their problem solving abilities?

4. Is there any relationship between the sub-factors of reflective thinking tendencies of pre-service teachers and their problem solving abilities?

5. Is there any relationship between reflective thinking tendencies and social problem solving abilities of pre-service teachers?

\section{Method}

\subsection{Research Model}

In this study, it is aimed to examine reflective thinking and problem solving of pre-service and to determine whether there is a significant relationship between reflective thinking and problem solving ability. From this aspect, the research has the quality of relational screening model. In relational screening model, it is aimed to determine the covariance between more than one variable and to determine its level (Karasar, 2009).

\subsection{Population and Sample}

The distribution of pre-service teachers studying at Faculty of Education at Kırşehir Ahi Evran University in academic year 2015-2016 and being chosen in accordance with the purpose of the research are seen in Table 1.

Table 1. Distributions according to Departments related to Study Population

\begin{tabular}{llll}
\hline Departments & Total Number of Students & Number of Participants & Valid Data Number \\
\hline Classroom Teaching & 102 & 86 & 81 \\
Pre-school Teaching & 54 & 40 & 37 \\
Primary School Math & 43 & 43 & 41 \\
Science Teaching & 77 & 75 & 70 \\
Turkish Teaching & 60 & 54 & 48 \\
Psychological Counseling and Guidance & 71 & 68 & 64 \\
Social Sciences Teaching & 80 & 70 & 65 \\
Computer and Instructional Technology & 45 & 36 & 32 \\
\hline Total & 532 & 472 & 438
\end{tabular}

When we look at Table 1, it is seen that 472 pre-service teachers determined by convenience sampling method that is one of the nonprobability sampling methods have a number that can be represent population of the study by taking $\% 98$ confidence interval and 0,02 amount of error into consideration among 532 pre-service teachers determined as the study 
population. Before we begin with analysis, it is examined whether there is missing data or not. After extracting data by looking at extreme values, analyses are done with 438 pre-service teachers among 472 pre-service teachers that are determined as a sample. Distributions related to the demographic features of 438 pre-service teachers are seen in Table 2.

Table 2. Frequency and Percentage Distributions related to the Demographic Distributions of Pre-service Teachers

\begin{tabular}{llll}
\hline Features & Categories & $f$ & $\%$ \\
\hline \multirow{4}{*}{ Undergraduate Program } & Classroom Teaching & 81 & 18.5 \\
& Pre-School Teaching & 37 & 8.4 \\
& Primary School Math & 42 & 9.6 \\
& Science Teaching & 69 & 15.8 \\
& Turkish Teaching & 48 & 11.0 \\
& Psychological Counseling and Guidance & 64 & 14.6 \\
& Social Sciences Teaching & 65 & 14.8 \\
& Computer and Instructional Technologies & 32 & 7.3 \\
\hline \multirow{3}{*}{ High-School Field Type } & Numerical & 197 & 45.0 \\
& Verbal & 149 & 34.0 \\
& & 92 & 21.0 \\
\hline Total & & 438 & 100.0 \\
\hline
\end{tabular}

As Table 2 shows, to the variable of undergraduate program, there are $81(\% 18.5)$ pre-service teachers in Classroom Teaching Department, 37 (\%8.4) in Primary-School Teaching Department, 42 (\%9.6) in Department of Primary School Math Education, 69 (\%15.8) in Science Teaching Department, 48 (\%11.0) in Turkish Teaching Department, 64 (\%14.6) in Department of Psychological Counseling and Guidance, 65 (\%7.3) in Social Sciences Teaching Department and 32 (\%7.3) in Department of Computer and Instructional Technologies. When the distribution of pre-service teachers according to the variable of high-school field type is taken into consideration, there are 197 (\%45.0) pre-service teachers graduated from equally-weighted section, 149(\%34.0) from numerical section and 92 (\%21.0) from verbal section. In general, there are 438 (\%100.0) pre-service teachers within the scope of this research.

\subsection{Data Collection Tools}

As being suitable for the purpose of the research, two scales are used other than the personal information form applied to the pre-service teachers. These scales;

\subsubsection{Reflective Thinking Tendency Scale (RTTS) for Teachers and Pre-Service Teachers}

The scale developed by Semerci (2007) includes seven sub-factors. Cronbach Alpha reliability co-efficients belonging to the sub-factors change between 0.36 and 0.79 . Whole reliability co-efficient of the scale is 0.91 . The scale includes 35 items as being 20 negative and 15 positive that are graded as five point likert scale.

\subsubsection{Social Problem Solving Inventory (PSI)-Short Form}

It is decided to use Social Problem Solving Inventory - Short Form which has 25 items and 4 factors, developed by D'Zurilla et al. (2002) and adapted to Turkish by Çekici (2009) to collect data related to the social problem solving abilities of the pre-service teachers.

\subsection{Data Analysis}

The data collected in accordance with the purpose of the research are processed into SPSS-21 packaged software. Frequency analysis related to the distribution of pre-service teachers according to their undergraduate programs and high-school field types is examined. Descriptive statistics (mean, standard deviation, minimum and maximum values) belonging to each sub-factors and generalities of the scales are included. In order to determine the relationship between reflective thinking tendency and social problem solving abilities of pre-service teachers Pearson Correlation Analysis has been examined. 


\section{Results}

\subsection{First Sub-Problem: In What Level Are the Reflective Thinking Tendencies of Pre-Service Teachers?}

Table 3. Descriptive Statistics belonging to Tendencies related to the Sub-Factors and Generality of Reflective Thinking Tendency Scale for Pre-service Teachers

\begin{tabular}{llllll}
\hline Scales & $\mathrm{N}$ & Minimum & Maximum & Mean & $\mathrm{S}$ \\
\hline Constant and Oriented Thinking & 438 & 15.00 & 35.00 & 27.71 & 4.20 \\
Open-Mindedness & 438 & 8.00 & 30.00 & 25.71 & 5.06 \\
Interrogative and Effective Education & 438 & 5.00 & 25.00 & 21.71 & 4.19 \\
Teaching Responsibility and Scientificity & 438 & 5.00 & 25.00 & 19.28 & 4.21 \\
Researcher & 438 & 10.00 & 30.00 & 22.94 & 4.35 \\
Being Visionary and Sincere & 438 & 4.00 & 20.00 & 15.87 & 3.28 \\
Viewing to Vocation & 438 & 2.00 & 10.00 & 8.14 & 1.96 \\
Reflective Thinking Tendency & 438 & 71.00 & 175.00 & 141.40 & 21.16 \\
\hline
\end{tabular}

As Table 3 shows, minimum point level belonging to reflective thinking tendencies of pre-service teachers towards constant and oriented thinking is 15 and the maximum one is 35 . It is also seen that tendency means in this factor are $\mathrm{X}=27.71$ ( $\mathrm{S}=4.20$ ). Skewness value related to reflective thinking tendencies of pre-service teachers towards constant and oriented thinking is -.43; that is to say, they show a distribution a little above the tendency mean. Minimum point level belonging to reflective thinking tendencies of pre-service teachers towards open-mindedness is 8 , and the maximum one is 30 . Tendency means in this factor are $X=25.71$ ( $S=5.06)$. Skewness value related to reflective thinking tendencies of pre-service teachers towards open-mindedness is -.98; that is, they show a distribution above the tendency mean. It is seen that minimum point level belonging to reflective thinking tendencies of pre-service teachers towards interrogative and effective education is 5 , and the maximum one is 25 . Tendency means in this factor are $\mathrm{X}=21.71$ $(\mathrm{S}=4.19)$. Skewness value related to reflective thinking tendencies of pre-service teachers towards interrogative and effective education is -.92; namely, they show a distribution above the tendency mean. Minimum point level belonging to reflective thinking tendencies of pre-service teachers towards teaching responsibility and scientificity is 5 , and the maximum one is 25 . And it is seen that tendency means in this factor are $X=19.28(S=4.21)$. Skewness value related to reflective thinking tendencies of pre-service teachers towards teaching responsibility and scientificity is -.73 ; namely, they show a distribution above the tendency mean. According to Table-3, minimum point level belonging to reflective thinking tendencies of pre-service teachers towards researcher is 10 , and the maximum one is 30 . Besides, tendency means in this factor are $X=22.94(S=4.35)$. Skewness value related to reflective thinking tendencies of pre-service teachers towards researcher is -.43; it means that they show a distribution a little above the tendency mean. Minimum point level belonging to reflective thinking tendencies of pre-service teachers towards being visionary and sincere is 4 , and the maximum one is 20. It is also seen that tendency means in this factor are $X=15.87$ ( $S=3.28$ ). Skewness value related to reflective thinking tendencies of pre-service teachers towards being visionary and sincere is -.88; that is to say, they show a distribution above the tendency mean. In terms of viewing to vocation, minimum point level belonging to reflective thinking tendencies of pre-service teachers is 2 , and the maximum one is 10 . It is also seen that tendency means in this factor are $\mathrm{X}=8.14$ ( $\mathrm{S}=1.96)$. Skewness value related to reflective thinking tendencies of pre-service teachers towards viewing to vocation is -.73; that is, they show a distribution above the tendency mean. Minimum point level belonging to reflective thinking tendencies of pre-service teachers is 71 , and the maximum one is 175 . It is also seen that tendency means related to reflective thinking are $X=141.80(S=21.16)$. Skewness value related to reflective thinking tendencies of pre-service teachers is -.63; that is, they show a distribution above the tendency mean.

\subsection{Second Sub-Problem: In What Level Are the Social Problems Solving Abilities of Pre-Service Teachers?}

Table 4. Descriptive Statistics belonging to Tendencies related to the Sub-Factors and Generality of Problem Solving Scale-Short Form

\begin{tabular}{|c|c|c|c|c|c|}
\hline Scales & $\mathrm{N}$ & Minimum & Maximum & Mean & $\mathrm{S}$ \\
\hline Negative Problem Orientation & 438 & 5.00 & 25.00 & 13.43 & 3.86 \\
\hline Positive Problem Orientation and Rationale Problem Solving & 438 & 15.00 & 50.00 & 36.45 & 6.50 \\
\hline Avoidance Style & 438 & 5.00 & 25.00 & 11.02 & 4.12 \\
\hline Impulsivity/Carelessness Style & 438 & 5.00 & 25.00 & 12.43 & 3.86 \\
\hline Problem Solving & 438 & 35.00 & 104.00 & 73.33 & 10.09 \\
\hline
\end{tabular}

When we look at Table 4, it is seen that minimum point level of abilities belonging to negative problem orientation of 
pre-service teachers is 5 , and the maximum one is 25 . In this factor, ability means are $\mathrm{X}=13.43$ ( $\mathrm{S}=3.86$ ). In addition to this, skewness value related to the abilities of pre-service teachers towards negative problem solving is -.05; therefore, it shows a distribution a little above tendency mean. Minimum point level of positive problem orientation and rationale problem solving abilities of pre-service teachers is 15 , and the maximum one is 50 . It is seen that ability means are $\mathrm{X}=36.45$ ( $\mathrm{S}=6.50)$ in this factor. Skewness value related to the abilities of pre-service teachers towards positive problem solving and rationale problem solving is -.25 ; that is to say, it shows a distribution a little above tendency mean. It is seen that minimum point level of abilities belonging to avoidance style of pre-service teachers is 5 , and the maximum one is 25 . In this factor, ability means are $\mathrm{X}=11.02(\mathrm{~S}=4,12)$. Skewness value related to pre-service teachers' abilities belonging to the avoidance style is -.38; namely, it shows a distribution a little above tendency mean. As seen in Table 4, minimum point level of abilities belonging to impulsivity/carelessness style of pre-service teachers is 5 , and the maximum one is 25 . In this factor, ability means are $X=12.43$ ( $S=3.86)$. Skewness value related to pre-service teachers' abilities belonging to the impulsivity/carelessness style is -.29 ; it shows a distribution a little above tendency mean. Minimum point level of abilities belonging to problem solving abilities of pre-service teachers is 35 , and the maximum one is 104. Problem solving ability means are $X=73.33(S=10.00)$. It is also seen that skewness value related to social problem solving abilities of pre-service teachers is -.11 , and it means that it shows a distribution a little above tendency mean.

3.3 Third Sub-Problem: Is There Any Relationship between the Sub-Factors of Reflective Thinking Tendencies of Pre-Service Teachers and Their Problem Solving Abilities?

Table 5. Pearson Correlation Analysis Results Related to the Relationship between Average Points Obtained from the Sub-Factors of Reflective Thinking Tendencies of Pre-Service Teachers and Their Problem Solving Ability Points

\begin{tabular}{lll}
\hline $\mathrm{N}=438$ & & Problem Solving Ability \\
\hline \multirow{2}{*}{ Constant and Oriented Thinking } & $\mathrm{r}$ & $.74\left({ }^{*}\right)$ \\
Open-Mindedness & $\mathrm{p}$ & .000 \\
& $\mathrm{r}$ & $.62(*)$ \\
Interrrogative and Effective Teaching & $\mathrm{p}$ & .000 \\
& $\mathrm{r}$ & $.69\left(^{*}\right)$ \\
Teaching Responsibility and Scientificity & $\mathrm{p}$ & .000 \\
& $\mathrm{r}$ & $.68(*)$ \\
Researcher & $\mathrm{p}$ & .000 \\
& $\mathrm{r}$ & $.64(*)$ \\
Being Visionary and Sincere & $\mathrm{p}$ & .000 \\
& $\mathrm{r}$ & $.68(*)$ \\
Viewing to Vocation & $\mathrm{p}$ & .000 \\
& $\mathrm{r}$ & $.52(*)$ \\
\end{tabular}

*p<.05

When we look at Table-5, it can be seen that the relationship between sub-factors of reflective thinking tendencies of pre-service teachers and their problem solving abilities is examined. $T_{0} \mathrm{r}_{(438)}=.74, \mathrm{p}=.000<.05$, there is a positive, high-level and significant relationship between reflective thinking tendencies related to the sub-factor constant and oriented thinking and problem solving abilities. It is also seen that pre-service teachers' reflective thinking tendencies related to constant and oriented thinking explain $\% 55\left(\mathrm{r}^{2}=0.74 \mathrm{X} 0.74=0.55\right)$ of their social problem solving abilities.

To $\mathrm{r}_{(438)}=.62, \mathrm{p}=.000<.05$, there is a positive, a little above medium-level and significant relationship between pre-service teachers' reflective thinking tendencies related to open-mindedness sub-factor and their social problem solving abilities. It is also seen that pre-service teachers' reflective thinking tendencies related to open-mindedness explain $\% 38\left(\mathrm{r}^{2}=0.62 \mathrm{X} 0.62=0.38\right)$ of their social problem solving abilities.

To $\mathrm{r}_{(438)}=.69, \mathrm{p}=.000<.05$, there is a positive, close to high-level and significant relationship between pre-service teachers' reflective thinking tendencies related to interrogative and effective teaching sub-factor and their social problem solving abilities. It is seen that pre-service teachers' reflective thinking tendencies related to interrogative and effective teaching explain $\% 48\left(r^{2}=0.69 \times 0.69=0.48\right)$ of their social problem solving abilities. 


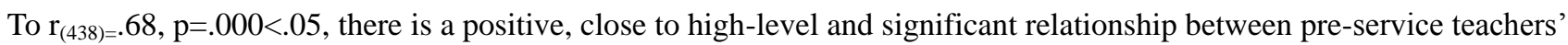
reflective thinking tendencies related to teaching responsibility and scientificity sub-factor and their social problem solving abilities. It is also seen that pre-service teachers' reflective thinking tendencies related to teaching responsibility and scientificity explain $\% 46\left(\mathrm{r}^{2}=0.68 \mathrm{X} 0.68=0.46\right)$ of their social problem solving abilities.

To $\mathrm{r}_{(438)}=.64, \mathrm{p}=.000<.05$, there is a positive, a little above medium-level and significant relationship between pre-service teachers' reflective thinking tendencies related to researcher sub-factor and their social problem solving abilities. It is also seen that pre-service teachers' reflective thinking tendencies related to researcher explain \%41 $\left(r^{2}=0.64 X 0.64=0.41\right)$ of their social problem solving abilities.

To $\mathrm{r}_{(438)=} .68, \mathrm{p}=.000<.05$, there is a positive, high-level and significant relationship between pre-service teachers' reflective thinking tendencies related to being visionary and sincere sub-factor and their social problem solving abilities. And pre-service teachers' reflective thinking tendencies related to researcher explain $\% 46\left(r^{2}=0.68 X 0.68=0.46\right)$ of their social problem solving abilities.

To $\mathrm{r}_{(438)}=.52, \mathrm{p}=.000<.05$, there is a positive, medium-level and significant relationship between pre-service teachers' reflective thinking tendencies related to viewing to vocation sub-factor and their social problem solving abilities. It is seen that pre-service teachers' reflective thinking tendencies related to viewing to vocation explain \%27 $\left(\mathrm{r}^{2}=0.52 \mathrm{X} 0.52=0.27\right)$ of their social problem solving abilities.

3.4 Forth Sub-Problem: Is There Any Relationship between Social Problem Solving Sub-Factors and Reflective Thinking Tendencies Of Pre-Service Teachers?

Table 6. Pearson Correlation Analysis Results Related to the Relationship between Average Points Obtained from the Sub-Factors of Social Problem Solving Ability of Pre-Service Teachers and Their Reflective Thinking Tendency Points

\begin{tabular}{lll}
\hline $\mathrm{N}=438$ & & Reflective Thinking Tendencies \\
\hline \multirow{2}{*}{ Negative Problem Orientation } & $\mathrm{r}$ & $-.43\left(^{*}\right)$ \\
& $\mathrm{p}$ & .000 \\
Positive Problem Orientation and Rationale Problem Solving & $\mathrm{r}$ & $.57\left(^{*}\right)$ \\
& $\mathrm{p}$ & .000 \\
Avoidance Style & $\mathrm{r}$ & $.67\left(^{*}\right)$ \\
Impulsivity/ & $\mathrm{p}$ & .000 \\
Carelessness Style & $\mathrm{r}$ & $-.73\left(^{*}\right)$ \\
\hline
\end{tabular}

$* \mathrm{p}<.05$

When we look at Table 6, it is seen that the relationship between the sub-factor of social problem solving ability and reflective thinking tendencies of pre-service teachers is examined. According to $\mathrm{r}_{(438)}=-.43, \mathrm{p}=.000<.05$, there is a negative, medium-level and significant relationship between pre-service teachers' social problem solving abilities related to the sub-factor "Negative Problem Orientation" and their reflective thinking tendencies. Pre-service teachers' problem solving abilities related to negative problem orientation explains $\% 18\left(r^{2}=-0.43 X-0.43=0.18\right)$ of their reflective thinking tendencies. When the negative problem orientation points of pre-service teachers increase, their reflective thinking tendencies decrease.

To $\mathrm{r}_{(438)}=.57, \mathrm{p}=.000<.05$, there is a positive, medium-level and significant relationship between pre-service teachers' social problem solving abilities related to positive problem orientation and rationale problem solving sub-factor and their reflective thinking tendencies. It is seen that pre-service teachers' problem solving abilities related to positive problem orientation and rationale problem solving explain $\% 32\left(\mathrm{r}^{2}=0.57 \mathrm{X} 0.57=0.32\right)$ of their reflective thinking tendencies.

To $\mathrm{r}_{(438)}=.67, \mathrm{p}=.000<.05$, there is a positive, close to high-level and significant relationship between pre-service teachers' social problem solving abilities related to avoidance style sub-factor and their reflective thinking tendencies. It is seen that pre-service teachers' problem solving abilities related to avoidance style explain $\% 45\left(r^{2}=0.67 \mathrm{X} 0.67=0.45\right)$ of their reflective thinking tendencies.

To $\mathrm{r}_{(438)}=-.73, \mathrm{p}=.000<.05$, there is a negative, high-level and significant relationship between pre-service teachers' social problem solving abilities related to impulsivity/carelessness style sub-factor and their reflective thinking tendencies. It is seen that pre-service teachers' problem solving abilities related to impulsivity/carelessness style explain $\% 53\left(r^{2}=-0.73 X-0.73=0.18\right)$ of their reflective thinking tendencies. When the impulsivity/carelessness style 
points of pre-service teachers increase, their reflective thinking tendencies decrease.

3.5 Fifth Sub-Problem: Is There Any Relationship between reflective thinking tendencies and Social Problem Solving Abilities of Pre-Service Teachers?

Table 7. The Results of Pearson Correlation Analysis belonging to the Realtionship between Reflective Thinking Tendencies and Social Problem Solving Abilities of Pre-service Teachers

\begin{tabular}{lll}
\hline & & Social Problem Solving Ability \\
\hline & $\mathrm{r}$ & $0.66\left(^{*}\right)$ \\
Reflective Thinking Tendency & $\mathrm{p}$ & .000 \\
& $\mathrm{~N}$ & 438 \\
\hline
\end{tabular}

$* \mathrm{p}<.05$

When Table 7 is examined, it is seen that there is a positive, close to high-level and significant relationship between reflective thinking tendencies and social problem solving abilities of pre-service teachers to $\mathrm{r}_{(438)}=0.66, \mathrm{p}=.000<.05$. Determination coefficient showing the effect of reflective thinking tendencies on social problem solving abilities of pre-service teachers is $r^{2}=0.44\left(r^{2}=0.66 \times 0.66=0.44\right)$. That is to say, reflective thinking tendencies of pre-service teachers explain $\% 44$ of social problem solving.

\section{Discussion}

The basic abilities that should be dwelled on both in the world and in Turkey have been mentioned in the theoretical review of literature. Accordingly, reflective thinking and problem solving ability of pre-service teachers is a topic that gains importance as from the beginning of their education life as a teacher without excepting their pre-service educations. Regarding that the teachers can reflect the thoughts of mass in question and have qualifications essential for solving problems they face both in daily life and classroom environment is a feature that should be taken into consideration while they are chosen to the profession (Ylldırım, Tabak \& Yavuz, 2012). Therefore, when the relationship between the sub-factors of reflective thinking tendencies and problem solving abilities of pre-service teachers is examined, having the high-level relationship between reflective thinking tendencies related to constant and oriented thinking and social problem solving abilities reveals obligation in review of literature as a research finding.

As a matter of course, globalization concept stated in education does not only mean that individuals have the values on base, apply them and adapt themselves (Bolat and Çelik, 2014, p. 163). However, new tendencies happen in education and their pursuit presents a necessity. Among these tendencies, abilities such as social problem solving ability, critical thinking and reflective thinking, assessment and evaluation, teaching services and determining the qualification of programs (Pektaş, 2010) are not one and only. It is also necessary to actualize these abilities in a complex way. Having the positive relationship between problem solving ability levels related to the positive problem orientation and rationale problem solving and reflective thinking tendencies reveals that. This finding shows similarity with Ergüven's master thesis (2011), Demir and Durdukoca's research (2012) in which teachers use their reflective thinking tendencies at a high level. When the international literature is examined, it is possible to see the similar results with the results in question (Adler, 1991; Clift, Houston \& Pugach, 1990; Goodman, 1984).

On the other hand, Kızılkaya and Aşkar (2009) state that problem solving ability is one of the abilities that all the individuals should have. They also express that reflection is observed ideally during the process of problem solving by drawing attention to reflective thinking emerges when a problem is perceived. Problem solving arises as one of the abilities that an individual should have. In this regard, it is thought that reflective thinking can have some contributions to the process of problem solving. And these contributions are the best in the process of problem solving. Increase in the reflective thinking tendencies in this study shows similarity with the finding that it causes approximately half of social problem solving levels (Aronson, Bridgeman \& Gefner, 1978; Lasley, 1980).

According to the study of Köksal and Demirel (2008), reflective thinking tendency contributes positively to the process of planning, practice and evaluation of pre-service teachers. In the study of Alp and Taşkin (2012) they use reflective thinking as part of the problem solving. Aforementioned result and dimensions are in the same direction with the result and findings of the study. As a matter of fact, when we look at the sub-factors of social problem solving inventory of pre-service teachers and their levels related to the overall, the result that they exhibit distribution above the average has the qualification of proving this. This result shows great similarity with the researches about reflective thinking and social problem solving ability of pre-service teachers done both nationally and internationally (Bayless, 1967; Posner, 1985; McClure, Chinsky and Larcen, 1978). 


\section{Conclusions}

The results related to the findings obtained from the reflective thinking tendency scale and social problem solving inventory-short form for teachers and pre-service teachers that are determined in line with the purpose of the research and applied to pre-service teachers are below:

When the levels of pre-service teachers related to the sub-factors and the generality of reflective thinking tendency scale are examined, it is concluded that they show better-than-average distribution; namely, reflective thinking tendencies of pre-service teachers in the research sample are close to high. When the levels of pre-service teachers related to the sub-factors and the generality of social problem solving scale are examined, it is concluded that they show better-than-average distribution; namely, social problem solving abilities of pre-service teachers in the research sample are close to high.

When the relationship between the sub-factors of reflective thinking tendencies and problem solving abilities of pre-service teachers is examined, it is concluded that there is a high-level relationship between reflective thinking tendencies and social problem solving abilities related to constant and oriented thinking; a little above medium-level and significant relationship between open-mindedness and researcher sub-factors and problem solving abilities; a medium-level relationship between reflective thinking tendencies and social problem solving abilities related to viewing to vocation sub-factor; a high-level significant relationship between reflective thinking tendencies and social problem solving abilities related to the sub-factors interrogative and effective teaching, teaching responsibility and scientificity, being visionary and sincere. It is also concluded that social problem solving abilities increase when the tendency levels of sub-factors related to the reflective thinking tendency scale.

When the relationship between problem solving abilities and reflective thinking tendencies belonging to the sub-factors of social problem solving ability scale is examined, there is a negative, medium-level and significant relationship between problem solving abilities and reflective thinking tendencies related to the negative problem orientation; that is to say, reflective thinking tendency levels increase when the negative problem orientation levels increase. It is concluded that there is a positive, medium-level and significant relationship between problem solving abilities and reflective thinking tendencies related to the positive problem orientation and rationale problem solving; in other words, reflective thinking tendencies increase when the problem solving ability levels related to the positive problem orientation and rationale problem solving increase. With relation to the avoidance style, there is a positive, high-level and significant relationship between problem solving abilities and reflective thinking tendencies. It means that the reflective thinking tendency increases when the problem solving ability related to the avoidance style increases. Another conclusion is that there is a negative, high-level and significant relationship between the problem solving ability related to the impulsivity/carelessness style and the reflective thinking tendencies; that is, the reflective thinking tendencies decrease when the problem solving ability related to the impulsivity/carelessness style increases.

It is concluded that there is a significant and close to high-level relationship between reflective thinking tendencies and social problem solving abilities of pre-service teachers. The increase on reflective thinking tendencies causes approximately half as much increase on social problem solving abilities, and it can be said that it explains almost half of it.

Pre-service teachers should be oriented to activities that they can increase their problem solving abilities. Lessons related to the lessons towards problem solving abilities and seminars of instructors related to the topic should be included. That some issues can increase reflective thinking tendencies and improve problem solving abilities should be explained and evaluated by examining the contents of formation lessons given to the pre-service teachers. The necessity of paving the way for solving social problems that pre-service teachers encounter in their social lives and especially the ones that can affect their futures and the need for giving suitable pedagogical support to this will shed light on the next studies. It is thought that designing teaching-learning process relocating students to the center during the undergraduate education and that instructors use them in teaching lesson are important both for increasing reflective thinking tendencies of pre-service teachers and for improving their problem solving abilities.

\section{References}

Adler, S. (1991). Forming a critical pedagogy in the social studies methods class: The use of imaginative literature. In B.R. Tabachnick \& K.M. Zeichner (Eds.). Issues and practices in inquire-oriented teacher education (pp.77-90). NY: The Falmer.

Alp, S., \& Taşkın, Ç. Ş. (2012). Critical thinking and problem solving: Teachers' use of reflective thinking. Journal of Buca Education Faculty, 33.

Alp, S., \& Taşkın, Ş. Ç. (2008). The importance of reflective thinking in education and the development of reflective thinking. Journal of National Education, 178, 311-320. 
Aronson, E., Bridgeman, D., \& Gefner, R. (1978). The effects of a cooperative classroom structure on student behavior and attitudes. In D. Bar-Tal \& L. Saxe (Eds.), Social psychology of education, DC: Hemisphere.

Aslan, G. (2009). An examination of the relationship between classroom teachers' reflective thinking tendencies and trait anxiety levels (Master thesis). Retrieved from https://tez.yok.gov.tr

Bartlett, L. (1990). Teacher development through reflective teaching. Second language teacher education, 202-214.

Bayless, O. L. (1967). An alternative pattern for problem solving discussion. Journal of Communication, 17, 188-197. https://doi.org/10.1111/j.1460-2466.1967.tb01177.x

Bolat, Y., \& Çelik, A. (2014). Effects of globalization on the Turkish educatıon system and reflections in primary school teacher program. Route Educational and Social Science Journal, 1(3), 158-175. https://doi.org/10.17121/ressjournal.80

Bölükbaş, F. (2004). Teaching Turkish as a foreign language with reflective teaching. Teaching Turkish in the World -6 . Symposium, (15-16 April 2004). Ankara.

Çekici, F. (2009). The effects of skills enhancement group program which is based on problem solving therapy on college students' social problem solving skills, anger related behaviours and cognitions, trait-anxiety levels (Doctoral Dissertation). Retrieved from https://tez.yok.gov.tr

Clift, R., Houston, W., \& Pugach, M. (1990). Encouraging reflective practice in education: An analysis of issues and programs. NY: Teachers College.

Copeland, W. D., Birmingham, C., De La Cruz, E., \& Lewin, B. (1993). The reflective practitioner in teaching: toward a research agenda. Teaching \& Teacher Education, 19(4) 347-359. https://doi.org/10.1016/0742-051X(93)90002-X

Demir, M., \& Durdurkoca, F. Ş. (2012). Reflective thinking levels of primary school teachers according to some variables and the relevance of teacher qualities in their mind to the qualities of reflective teacher. Mustafa Kemal University Journal of Social Sciences Institute, 9(20), 357-374

Demirel, Ö. (2004). Teaching art. Ankara: Pegem

D'Zurilla, T. J., \& Goldfried, M. R. (1971). Problem Solving and Behaviour Modification. Journal of Abnormal Psychology, 78, 107-126. https://doi.org/10.1037/h0031360

Ergüven, S. (2011). An investigation of teachers reflective thinking skills in terms of various factors (Master thesis). Retrieved from https://tez.yok.gov.tr

Erton, İ. (2014). Quality Control in Education with Reflective Teaching. Cumhuriyet Newspaper Science and Technology: Ankara.

Gedik, H., Akhan, N. E., \& Kılıçoğlu, G. (2014). The reflective thinking tendency of social studies candidate teachers. Mediterranean Journal of Humanities, 4(2), 113-130. https://doi.org/10.13114/MJH.201428432

Genç, S. Z., \& Kalafat, T. (2010). Prospective teachers' problem solving skills and emphatic skills. Journal of Theoretical Educational Science, 3(2), 135-147.

Goodman, J. (1984). Reflection and teacher education: A case study and theoretical analysis. Interchange, 15(3), 9-26. https://doi.org/10.1007/BF01807939

Gözütok, F. D. (2006). Teaching Principles and Methods. Ankara: Ekinoks

Güçlü, N. (2003). Problem solving skills of high school principals. Journal of National Education, (160), 273-279.

Hatton, N., \& Smith, D. (1995). Reflection in teacher education: Towards definition and implementation. Teaching \& Teacher Education, 11(1) 33-49. https://doi.org/10.1016/0742-051X(94)00012-U

Hong, Y. C., \& Choi, I. (2011). Three dimensions of reflective thinking in solving design problems: A conceptual model. Education Technology Research Development, 59(5), 687-710. https://doi.org/10.1007/s11423-011-9202-9

Karaca, N. H., Aral, N., \& Karaca, L. (2013). A study of problem solving skills and self respect of preschool teachers. Journal of Research in Education and Teaching, 2(3).

Karasar, N. (2009). Scientific Research Method, Ankara: Nobel

Kılınç, H., H. (2010). Primary first and second stages teachers' reflective thinking tendencies (An example of Elazığ city). (Master thesis). Retrieved from https://tez.yok.gov.tr

Kızılkaya, G., \& Aşkar, P. (2009). The development of a reflective thinking skill scale towards problem solving. Education and Science, 34(154), 82-92. 
Köksal, N., \& Demirel, Ö. (2008). The contributions of reflective thinking to pre-service teachers' teaching practice. $H$. U. Journal of Education, 34(34), 189-203.

Korkut, F. (2004). School Based Preventive Counseling and Psychological Counseling. Ankara: An1

Lasley, T. (1980). Preservice teacher beliefs about teaching. Journal of Teacher Education, 31(4), 38-41. https://doi.org/10.1177/002248718003100410

McClure, L. F., Chinsky, J. M., \& Larcen, S. W. (1978). Enhancing social problem- solving performance in an elementary school setting. Journal of Educational Psychology, 70, 504-513. https://doi.org/10.1037/0022-0663.70.4.504

Pektaş, S. (2010). The analysis of teacher candidates' competency perceptions on measurement and assessment (Master thesis). Retrieved from https://tez.yok.gov.tr

Posner, G. (1985). Field experience: A guide to reflective teaching. NY: Longman.

Şahin, N., Şahin, N. H., \& Heppner, P. P. (1993). Psychometric properties of the Problem Solving Inventory in a group of Turkish university students. Cognitive Therapy and Research, 17, 379-396. https://doi.org/10.1007/BF01177661

Saracaloğlu, A. S., Yenice, N., \& Karasakaloğlu, N. (2009). The relationship between communication and problem solving skills and reading interest and habits of candidate teachers'. Journal of Yuzuncu Yll University Education Faculty, VI(II), 166-185.

Semerci, Ç. (2007). Developing a reflective thinking tendency scale for teachers and student teachers, Educational Sciences: Theory \& Practice, 7(3).

Terzi, Ş. (2003). Perception of problem solving skills among sixth graders, Journal of Turkish Educational Sciences, $1(2), 221-232$.

Tican, C. (2013). The effects of reflective thinking-based teaching activities on pre-service teachers' reflective thinking skills, critical thinking skills, democratic attitudes and academic achievement (Doctoral Dissertation). Retrieved from https://tez.yok.gov.tr

Ünver, G. (2003). Reflective thinking. Ankara: Pegem

Üstun, A., \& Bozkurt, E. (2003). Some occupational factors affecting gore problem solving skills for elementary school principals' self-perceptions, Gazi University Kastamonu Education Journal, 11(1), 13-20.

Üstün, G. (2011). Investigate the relationship between the reflective thinking tendency and democratic attitude of class teachers. (Master thesis). Retrieved from https://tez.yok.gov.tr

Yiğit, R. (2013). Examination of Relationship between Well-being of Teacher candidates and Levels of Social Problem Solving Skill. Elementary Education Online, 12(2), 550-560

Yıldırım, K., Tabak, H., \& Yavuz, B. (2012). The level of correspondence between teachers' competencies introduced by mone and the test of educational sciences of state employee selection exam. Journal of Turkish Educational Sciences, 10(4), 751-778.

Yorulmaz, M. (2006). Evaluation of primary school teachers view and practices relating to the reflective thinking (An example of Diyarbakır city) (Master thesis). Retrieved from https://tez.yok.gov.tr

Yost, D. S., Senter, S. M., \& Baily, A. F. (2000). An examination of the construct of critical reflection: implications for teacher education programming in the $21 \mathrm{st}$ century. Journal of Teacher Education, 51(1). https://doi.org/10.1177/002248710005100105

\section{Copyrights}

Copyright for this article is retained by the author(s), with first publication rights granted to the journal.

This is an open-access article distributed under the terms and conditions of the Creative Commons Attribution license which permits unrestricted use, distribution, and reproduction in any medium, provided the original work is properly cited. 